\title{
Increased insulin demand promotes while pioglitazone prevents pancreatic beta cell apoptosis in $\boldsymbol{W f} \mathbf{1}$ knockout mice
}

\author{
M. Akiyama • M. Hatanaka • Y. Ohta • K. Ueda • \\ A. Yanai • Y. Uehara • K. Tanabe • M. Tsuru • \\ M. Miyazaki • S. Saeki • T. Saito • K. Shinoda • Y. Oka • \\ Y. Tanizawa
}

Received: 7 May 2008 / Accepted: 29 December 2008 / Published online: 4 February 2009

(C) Springer-Verlag 2009

\begin{abstract}
Aims/hypothesis The WFS1 gene encodes an endoplasmic reticulum (ER) membrane-embedded protein called Wolfram syndrome 1 protein, homozygous mutations of which cause selective beta cell loss in humans. The function(s) of this protein and the mechanism by which the mutations of this gene cause beta cell death are still not fully understood. We hypothesised that increased insulin demand as a result of obesity/insulin resistance causes ER stress in pancreatic beta cells, thereby promoting beta cell death.

Methods We studied the effect of breeding $W f S 1^{-/}$mice on a C57BL/6J background with mild obesity and insulin resistance, by introducing the agouti lethal yellow mutation $\left(A^{y} / a\right)$. We also treated the mice with pioglitazone.
\end{abstract}

Electronic supplementary material The online version of this article (doi:10.1007/s00125-009-1270-6) contains supplementary material, which is available to authorised users.

\footnotetext{
M. Akiyama $\cdot$ M. Hatanaka $\cdot$ Y. Ohta $\cdot$ K. Tanabe $\cdot$ M. Tsuru $\cdot$

M. Miyazaki $\cdot$ Y. Tanizawa $(\bowtie)$

Division of Endocrinology, Metabolism,

Hematological Sciences and Therapeutics,

Department of Bio-Signal Analysis,

Yamaguchi University Graduate School of Medicine,

1-1-1 Minami Kogushi,

Ube, Yamaguchi 755-8505, Japan

e-mail: tanizawa@yamaguchi-u.ac.jp

K. Ueda
}

Health Service Center, Organization for University Education,

Yamaguchi University,

Ube, Yamaguchi, Japan

A. Yanai $\cdot$ K. Shinoda

Division of Neuroanatomy, Department of Neuroscience,

Yamaguchi University Graduate School of Medicine,

Ube, Yamaguchi, Japan
Results $\mathrm{WfS}_{\mathrm{S}} \mathrm{T}^{-/}$mice bred on a $\mathrm{C} 57 \mathrm{BL} / 6 \mathrm{~J}$ background rarely develop overt diabetes by 24 weeks of age, showing only mild beta cell loss. However, $W f_{S} 1^{-/-} A^{y} / a$ mice developed selective beta cell loss and severe insulin-deficient diabetes as early as 8 weeks. This beta cell loss was due to apoptosis. In $W f s 1^{+/+} A^{y} / a$ islets, levels of ER chaperone immunoglobulin-binding protein $(\mathrm{BiP}) / 78 \mathrm{kDa}$ glucoseregulated protein (GRP78) and phosphorylation of eukaryotic translation initiation factor 2, subunit $\alpha$ (eIF2 $\alpha$ ) apparently increased. Levels of both were further increased in $\mathrm{WfS}_{S} \mathrm{I}^{-/}$ $A^{y} / a$ murine islets. Electron micrography revealed markedly dilated ERs in $W f s 1^{-/-} A^{y} / a$ murine beta cells. Interestingly, pioglitazone treatment protected beta cells from apoptosis and almost completely prevented diabetes development.
Y. Uehara $\cdot$ S. Saeki $\cdot$ T. Saito

Applied Medical Engineering Science,

Yamaguchi University Graduate School of Medicine,

Ube, Yamaguchi, Japan

K. Tanabe

The Japan Health Science Foundation,

Tokyo, Japan

Y. Oka

Division of Molecular Metabolism and Diabetes,

Department of Internal Medicine,

Tohoku University Graduate School of Medicine,

Sendai, Japan 
Conclusions/interpretation $W f_{S} 1$-deficient beta cells are susceptible to ER stress. Increased insulin demand prompts apoptosis in such cells in vivo. Pioglitazone, remarkably, suppresses this process and prevents diabetes. As common WFS1 gene variants have recently been shown to confer a risk of type 2 diabetes, our findings may be relevant to the gradual but progressive loss of beta cells in type 2 diabetes.

Keywords Apoptosis · Diabetes mellitus .

Endoplasmic reticulum - Endoplasmic reticulum stress .

Insulin · Pancreatic beta cell $\cdot$ Pioglitazone .

Wolfram syndrome

$\begin{array}{ll}\text { Abbreviations } \\ \text { eIF2 } \alpha & \text { Eukaryotic translation initiation factor 2,subunit } \alpha \\ \text { ER } & \text { Endoplasmic reticulum } \\ \text { GRP78 } & 78 \mathrm{kDa} \text { Glucose-regulated protein } \\ \text { GRP94 } & 94 \mathrm{kDa} \text { Glucose-regulated protein } \\ \text { ipGTT } & \text { Intraperitoneal glucose tolerance test } \\ \text { IRE1 } & \text { Inositol-requiring protein 1 } \\ \text { ITT } & \text { Insulin tolerance test } \\ \text { UPR } & \text { Unfolded protein response } \\ \text { WFS1 } & \text { Wolfram syndrome 1 } \\ \text { WT } & \text { Wild-type }\end{array}$

\section{Introduction}

Many obese individuals with marked insulin resistance do not develop overt diabetes. However, in individuals destined to develop type 2 diabetes, pancreatic beta cells fail to produce enough insulin to meet systemic demand. This beta cell failure is caused by insufficient beta cell response to glucose and inadequate beta cell mass expansion [1]. Recently, several reports have convincingly confirmed the contribution of beta cell mass reduction to type 2 diabetes $[2,3]$, at least in its advanced stages. Although the cause of this decrease is unknown, increased apoptosis may play an important role [1, 2]. In addition to genetic factors, processes involving glucotoxicity and/or lipotoxicity are likely to be contributory [4]. Endoplasmic reticulum (ER) stress has also recently emerged as a candidate mechanism [5-7].

Wolfram syndrome is a rare recessively inherited genetic disorder, characterised by juvenile-onset diabetes mellitus and progressive optic atrophy [8]. Several neuro-psychiatric illnesses may also be present [9]. Beta cells are selectively lost from the pancreatic islets and this loss is genetically programmed [10]. Our group and others previously identified the Wolfram syndrome gene, designating it WFS1 [11] or wolframin [12] and showing that it is localised primarily in the ER [13, 14]. Homozygous $W f_{S} 1$ knockout mice developed glucose intolerance. However, the diabetic phenotype of the $W f_{S} 1^{-/-}$mouse was milder than that seen in Wolfram syndrome patients and was largely dependent on genetic background [15].

Despite intensive studies, the precise function of the Wolfram syndrome 1 (WFS1) protein is still largely unknown. It may regulate ER calcium homeostasis by serving as an ER cation channel [16, 17]. Recently the WFS1 protein was also suggested to be a putative chaperone for the $\mathrm{Na} / \mathrm{K}$ ATPase b1 subunit in the ER [18]. However, it is certain that its function is closely related to ER stress responses. ER stress induces $W f_{S} 1$ expression and, in turn, loss of WFS1 protein exacerbates ER stress [15, 19-21]. Furthermore, $W f_{S} 1^{-/-}$islet cells are susceptible to ER stress-induced apoptosis [15, 21, 22]. ER stress is induced under conditions such as overload of protein synthesis/processing, accumulation of structurally abnormal proteins, disturbance of post-translational modification and ER calcium homeostasis abnormalities. When ER stress develops, cells respond by unfolded protein response (UPR), facilitating protein folding via the induction of chaperone proteins, attenuation of translations, as well as degradation of misfolded proteins, a process called ERassociated degradation [23-25]. If the stress is severe, apoptosis is induced. Accumulating evidence suggests that a high level of ER stress or defective ER stress signalling causes beta cell death and that diabetes thereby develops [26-30].

We wished to test in vivo the hypothesis that beta cell loss in $W f S 1^{-/}$mice is caused by an inability to cope with ER stress. The agouti yellow $\left(A^{y} / a\right)$ mouse is a genetic model of mild obesity/insulin resistance with compensatory beta cell hyperplasia [31]. In this mouse, ectopically expressed agouti protein promotes food intake and weight gain by antagonising signalling at melanocortin-4 receptor in the hypothalamus. ER stress is likely to have been induced in these beta cells by increased insulin synthesis and secretion demands, and also by elevated serum NEFA [32]. As $W f_{S} 1^{-/}$mice on the C57BL/6J background rarely develop overt diabetes by 24 weeks, we introduced the $A^{y}$ mutation into $\mathrm{C} 57 \mathrm{BL} / 6 \mathrm{~J} W f_{S} 1^{--}$mice and assessed the consequences. Furthermore, we treated $W f_{S} 1^{-/-}$mice with pioglitazone, which ameliorates insulin resistance.

\section{Methods}

Animals All experimental protocols were approved by the Ethics of Animal Experimentation Committee at Yamaguchi University School of Medicine.

The $W f_{S} 1^{-/}$mice had a C57BL/6J background [15]. The Agouti yellow mice (C57BL/6JHamSlc- $A^{y}$ ) were obtained from M. Nishimura (Nagoya University Graduate School of Medicine, Nagoya, Japan) and Japan SLC 
(Hamamatsu, Japan). We used male mice for all experiments. The mice were kept under standard, specific pathogen-free conditions with a constant dark/light cycle and free access to standard mouse chow (MF; Oriental Yeast, Tokyo, Japan) and water. The high-fat diet (rodent diet with 60\% energy from fat; D12492) was purchased from Research Diet (New Brunswick, NJ, USA) and was freely accessible. For pioglitazone treatment, mice were fed standard mouse chow with $0.01 \%$ pioglitazone (wt/wt) from the age of 4 weeks. Pioglitazone was provided by Takeda Pharmaceutical (Osaka, Japan).

Generation of $W S_{S} 1^{-/} A^{y} / a$ mice To generate $A^{y} / a$ mice lacking the $W f_{S} 1$ gene, $W f_{S} 1^{-/-}$mice were bred with $A^{y} / a$ mice to create the compound heterozygote $\left(W f_{S} 1^{+/-} A^{y / a}\right)$. This heterozygote was bred with $W f_{S} 1^{+/-} a / a$, and $W f_{S} 1^{-/-}$ $A^{y} / a, W f_{S} 1^{+/+} A^{y} / a, W f_{S} 1^{-/-} a / a$ and $W f_{S} 1^{+/+} a / a$ (wild-type [WT]) offspring were identified.

The $W f_{S} 1$ genotype was determined by PCR. We used the sense primer 5'-CCCAGTTCTTGCTTTACCAC CAGG-3' and the anti-sense primers 5'-GCCTTCTTGAC GAGTTCTTCTGA-3' (derived from the neomycin resistance gene) and 5'-ACTTCGTCCAGCACTGGGGTCAG-3' (derived from the $W f_{S} 1$ gene). $A^{y} / a$ mice were identified by coat colour.

Physiological studies Body weights were measured weekly. Blood samples were collected from the tail vein. Non-fasting blood glucose was measured by the glucose oxidase method using a GlucoCard device (Arkray, Kyoto, Japan). Serum insulin levels were determined using an insulin ELISA kit (Morinaga Institute of Biological Science, Tokyo, Japan). Serum triacylglycerol was measured by high-performance liquid chromatography at Skylight Biotech (Akita, Japan), according to the procedure described by Usui et al. [33]. Intraperitoneal glucose tolerance test (ipGTT) and insulin tolerance test (ITT) were performed at 8 weeks of age.

Pancreatic insulin content Pancreases were removed and homogenised in acid/ethanol $(0.7 \mathrm{~mol} / 1 \mathrm{HCl} /$ ethanol 25:75 plus $0.1 \%$ Triton X-100 (vol./vol.)) and left at $4^{\circ} \mathrm{C}$ for $48 \mathrm{~h}$, with sonication every $24 \mathrm{~h}$. Homogenates were then centrifuged $(3,000 \mathrm{~g}$ for $15 \mathrm{~min})$ and the insulin content of the acid/ethanol supernatant fraction was measured using insulin ELISA. Protein in tissue extracts was determined using the BCA protein assay reagent.

Immunostaining and morphometry Formalin-fixed paraffinembedded sections were de-paraffinised and re-hydrated, then incubated with primary antibodies. For immunofluorescent staining, appropriate FITC-conjugated or Cy3-conjugated anti-IgG was used. Detailed antibody information is given in the Electronic supplementary material (ESM). Immunohisto- chemical analyses were performed, with at least three animals for each condition being killed for the purpose. For measurement of beta cell area, more than five pancreatic tissue sections per animal were randomly selected and stained with anti-insulin $\operatorname{IgG} / 3,3^{\prime}$-diaminobenzidine tetrahydrochloride and haematoxylin. Microscopic photoimages were taken with a charge-coupled device (CCD) camera and the pancreatic and beta cell areas were each estimated using a computer program (Y. Uehara, S. Saeki and S. Saito $\mathrm{S}$ unpublished results).

Tissue preparation and electron microscopy All animals were anaesthetised with sodium pentobarbital $(65 \mathrm{mg} / \mathrm{kg}$, i.p.) and intracardially perfused with $2 \%$ glutaraldehyde (vol./vol.) and 4\% paraformaldehyde (vol./vol.) in $0.1 \mathrm{~mol} / \mathrm{l}$ phosphate buffer $(\mathrm{pH} 7.4)$ containing $0.2 \%$ picric acid (vol./vol.). Pancreatic sections (1 mm thick) were post-fixed with $1 \% \mathrm{OsO}_{4}$ (wt/vol.), block-stained with $2 \%$ uranyl acetate (wt/vol.), dehydrated, infiltrated with propylene oxide, placed in a mixture of propylene oxide and Epoxy resin (1:1), and flat-embedded on siliconised glass slides in Epoxy resin. Ultrathin sections were made and mounted on to copper grids. To enhance contrast, they were double stained with $2 \%$ uranyl acetate (wt/vol.) and 1\% lead citrate (wt/vol.), and observed with a Hitachi H-7500 electron microscope (Hitachi High-Technologies, Tokyo, Japan) operating at $80 \mathrm{kV}$.

Mouse islet isolation and immunoblotting analysis Pancreatic islets were isolated as described previously [15]. For immunoblotting [34], approximately 100 islets from two to six mice were pooled, then immediately dissolved in lysis buffer containing $1 \%$ SDS $(50 \mathrm{mmol} / \mathrm{l}$ Tris- $\mathrm{HCl}$ [pH 6.8], 1\% SDS [wt/vol.], 10\% glycerol [wt/vol.] and $50 \mathrm{mmol} / 1$ dithiothreitol). Anti-WFS1 (N-terminus) antibody has been described previously [15]. For information on other antibodies, see ESM.

Statistical analysis Results are expressed as means $\pm \mathrm{SE}$. Differences between means were evaluated using ANOVA or Student's $t$ test as appropriate. Differences were considered significant at $p<0.05$.

\section{Results}

Characteristics of the mice Body weights were monitored weekly beginning at 4 weeks of age. $A^{y} / a$ mice $\left(W f_{S} 1^{+/+} A^{y} / a\right)$ were mildly, but significantly more obese than WT littermates $\left(W f_{S} 1^{+/+} a / a\right)$ by 6 weeks of age $(23.5 \pm 0.7$ vs $21.5 \pm$ $0.5 \mathrm{~g} ; p<0.05)$. Similarly, $W f_{S} 1^{-/-} A^{y} / a$ mice were also more obese than $W f_{S} 1^{-/}$a/a mice by 6 weeks of age $(23.9 \pm 0.3$ vs $20.6 \pm 0.2 \mathrm{~g} ; p<0.0001)$. However, $W f_{S} 1^{-/} A^{y} / a$ mice had 
lost their excess weight by 17 weeks of age (Fig. 1a). This is attributable to the development of overt diabetes due to severe insulin deficiency (Fig. 1b, c). In fact, non-fasted blood glucose levels of $W f_{S} 1^{-/-} A^{y} / a$ mice started to rise significantly from the age of 8 weeks, with all $\mathrm{WfS}_{S} 1^{-/-} A^{y} / a$ mice developing overt diabetes by 16 weeks of age (Fig. 1b). Ketosis manifested after age 16 weeks (data not shown). In contrast, blood glucose levels of $W f_{S} I^{+/+} A^{y} / a$ and $W f_{S} 1^{-/}$a/a mice did not differ from those of WT mice. We also examined plasma insulin levels of these mice. At 12 weeks of age, the plasma insulin levels of $W f_{S} I^{+/+} A^{y} / a$ mice were significantly higher than those of WT littermates, and $W f_{S} 1^{--}$a/a and
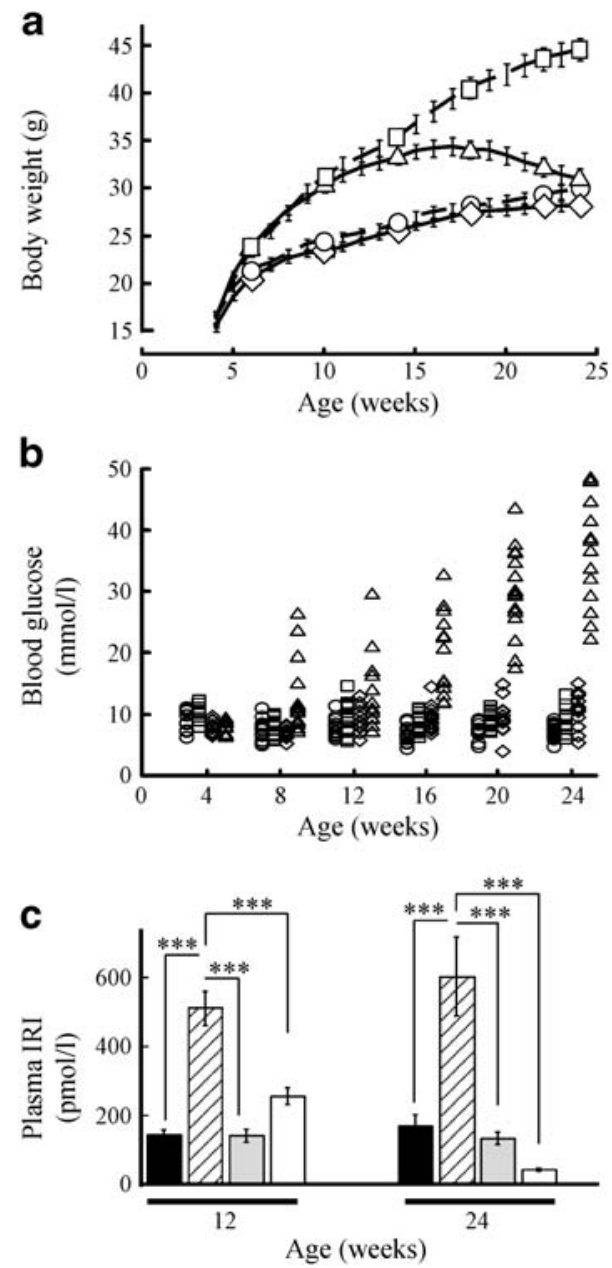

Fig. 1 Weight, blood glucose and insulin levels of $W f_{S} 1^{-1-} A^{y / a}$ and other mice. a Weight of $W f_{S} 1^{-/-} A^{y} / a$ (triangles), $W f_{S} 1^{+/+} A^{y} / a$ (squares), $W f_{S} 1^{-/-}$a/a (diamonds) and $W f_{S} 1^{+/+}$a/a (WT, circles) mice over the course of 24 weeks. Values are the means \pm SE for $n=14-21$ mice. b Non-fasted blood glucose levels in $W f_{S} 1^{-/} A^{y} / a, W f_{S} 1^{+/+} A^{y} / a, W f_{S} 1^{-/-}$ $a / a$ and WT mice; key as above, $n=11-16$. $p<0.05$ for $W f_{S} 1^{--} A^{y} / a$ vs $W f_{S} I^{+/+} A^{y} / a, W f_{S} 1^{-/} a / a$ and WT mice at 8 and 12 weeks; $p<0.001$ for $W f_{S} 1^{-/-} A^{y / a}$ vs $W f_{S} 1^{+/+} A^{y} / a, W f s 1^{-/-} a / a$ and WT mice at 16, 20 and 24 weeks. c Plasma immunoreactive insulin (IRI) levels in $\mathrm{WfS}_{\mathrm{S}} \mathrm{I}^{--}$ $A^{y} / a$ (white bars), $W f s 1^{+/+} A^{y} / a$ (hatched bars), $W f s 1^{-/}$a/a (grey bars) and WT (black bars) mice at 12 and 24 weeks of age. Data are presented as the means $\pm \mathrm{SE}$ for $n=7-13$ mice. ${ }^{* * *} p<0.001$
$W f_{S} 1^{-/} A^{y} / a$ mice. Interestingly, $W f_{S} I^{-/} A^{y} / a$ mice tended to be more hyperinsulinaemic than $W f S 1^{-/}$a/a and WT at this age, although the differences did not reach statistical significance. However, at 24 weeks of age, plasma insulin levels in $W f_{S} 1^{--} A^{y} / a$ mice were markedly decreased (Fig. 1c).

Intraperitoneal glucose tolerance test and ITT were performed at 8 weeks (Fig. 2). $W f_{S} I^{+/+} A^{y} / a$ mice, as well as $W f_{S} 1^{-/-} A^{y} / a$ mice, were already more insulin-resistant than $W f_{S} I^{+/+} a / a$ and $W f_{S} I^{-/-}$a/a mice at this young age (Fig. 2a, d). There was no statistical difference in the ITT curve between $W f_{S} I^{+/+} A^{y} / a$ and $W f_{S} I^{-/-} A^{y} / a$ mice. Although glucose tolerance of $W f_{S} I^{+++} A^{y} / a$ mice was normal because of compensatory elevated insulin secretion (Fig. 2b, c), this compensation was not found in $W f_{S} 1^{-/} A^{y} / a$ mice, whose glucose tolerance was impaired (Fig. 2e, f).

A similar, but milder phenotype was observed in the $W f_{S} 1^{-/}$a/a mice with high-fat diet-induced obesity (ESM Fig. 1). The high-fat diet caused obesity with hyperinsulinaemia in WT mice $\left(W f_{S} I^{+/+} a / a\right)$. However, these mice were normoglycaemic (ESM Fig. 1a). In contrast, a high-fat diet induced hyperglycaemia in $W f s 1^{-/-}$a/a mice, although less prominently than in $W f_{S} 1^{-/} A^{y} / a$ mice (mean non-fasting blood glucose $18.0 \pm 2.7 \mathrm{mmol} / \mathrm{l}, n=6$ vs $36.9 \pm$ $2.4 \mathrm{mmol} / \mathrm{l}, n=14$ at 24 weeks of age, $p<0.001$ ) (ESM Fig. 1b). Non-fasting insulin levels were lower, although not significantly, in high-fat diet-fed $W f_{S} 1^{+/+}$a/a than in $W f s 1^{+/+} A^{y} / a$ mice $(402.9 \pm 87.5 \mathrm{pmol} / 1, n=9$ vs $605.7 \pm$ 114.4, $n=7$ at age 24 weeks, $p>0.05$ ) (ESM Fig. 1c).

Acceleration of selective beta cell apoptosis We immunohistochemically investigated the cause of insulin deficiency. In 24-week-old $\mathrm{WfS}_{\mathrm{S}} \mathrm{I}^{+/+} A^{y} / \mathrm{a}$ mice, islets were hypertrophic and larger (Fig. 3b, f, j) than in WT (Fig. 3a, e, i) and $W f s 1^{-/}$a/a mice (Fig. 3c, g, k), reflecting responses to the increased insulin demand in $W f S I^{+/+} A^{y} / a$ mice. In the $W f_{S} 1^{-/}$a/a mice, insulin-positive beta cells were preserved (Fig. 3c, g) and there was no apparent difference from WT controls at this stage, except for a change in islet architecture (aberrant centric migration of alpha cells) (Fig. 3g, [15]). Interestingly and impressively, however, $W f_{S} 1^{--} A^{y} / a$ mice had small, irregularly shaped islets, in which insulin-positive beta cells were markedly decreased (Fig. 3d, h).

The results were confirmed by morphometric analysis showing that the insulin-positive area per pancreatic area in $W f_{S} 1^{+/+} A^{y} / a$ mice was increased as compared with that in WT and $W f_{S} 1^{-/}$ala mice. In $W f_{S} 1^{-/-} A^{y} / a$ mice, the insulin-positive area was markedly reduced (Fig. 4a), as was the pancreatic insulin content (Fig. 4b).

Time courses of beta cell loss in $W f_{S} 1^{--} A^{y} / a$ islets are shown in Fig. $3 \mathrm{~m}-\mathrm{o}$. In $W f_{S} 1^{-/} A^{y} / a$ mice, insulin-positive beta cells were selectively and severely depleted by 
Fig. 2 Insulin tolerance test and ipGTT. ITT $(0.75 \mathrm{U} / \mathrm{kg})(\mathbf{a}, \mathbf{d})$ and ipGTT $(2 \mathrm{~g} / \mathrm{kg})(\mathbf{b}, \mathbf{c}, \mathbf{e}, \mathbf{f})$ were performed at 8 weeks of age on $W f_{S} 1^{+/+} a / a$ (WT) (white circles), $\mathrm{Wfs}^{+/+} A^{y} / a$ (white squares), $W f s 1^{--}$a/a (black circles) and $W f_{S} 1^{--} A^{y} / a$ (black squares). Values are means \pm SEM, $n=3-10$ per group (ITT) and $n=7-10$ per group (ipGTT). ${ }^{*} p<0.05, * * p<0.01$ compared with the corresponding a/a mice a

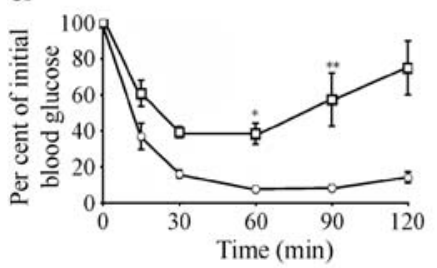

d

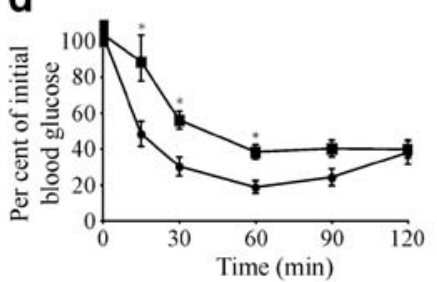

b

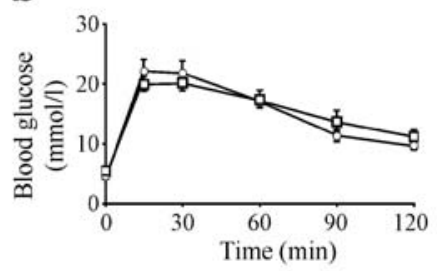

e

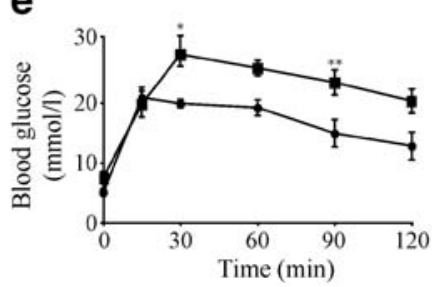

C

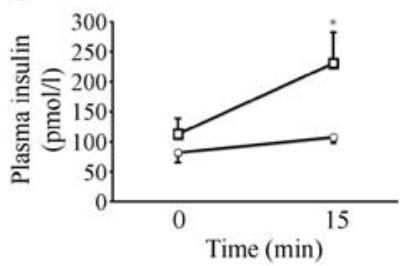

f

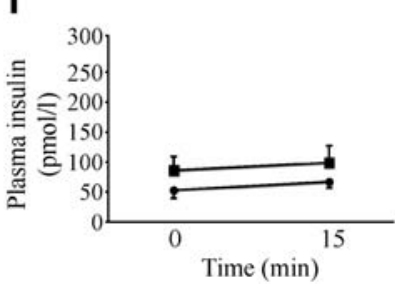

Fig. 3 Selective beta cell loss in islets of $W f_{S} 1^{-1-} A^{y} / a$ mice. a-I Pancreatic sections from 24-week-old $\mathrm{Wf}_{S} \mathrm{I}^{+/+}$a/a (WT), $W f_{S} I^{+/+} A^{y} / a, W f_{S} 1^{-/-} a / a$ and $W f_{S} 1^{-/-} A^{y} / a$ mice were immunostained for insulin (brown) (a-d), scale bar $100 \mathrm{~nm}$. e-h Immunofluorescence staining for insulin (green), glucagon (red) and (i-l) somatostatin (red). $\mathbf{m}-\mathbf{0}$ Representative time course of beta cell loss in islets from $W f S 1^{-/-} A^{y} / a$ mice. Insulin (green) and glucagon (red) were immunostained. At 8 weeks (m), most islets were indistinguishable from those of WT mice. By the 16th week (n), normal islet architecture had been destroyed and beta cell numbers were apparently decreased. By week 24 (o), few beta cells remained. p-s Immunohistochemistry results for pro-apoptotic active caspase-3 in pancreatic sections from WT (p), $W f_{S} I^{+/+} A^{y} / a(\mathbf{q})$, $W f_{S} 1^{-/} a / a(\mathbf{r})$ and $W f_{S} 1^{-/}$

$A^{y} / a$ mice (s). Activated caspase3 staining was performed at age 16 weeks. Positive cells were found in $W f_{S} 1^{-/-} A^{y} / a$ islets (s), but not in islets from other mice. Scale bar, $50 \mathrm{~nm}$
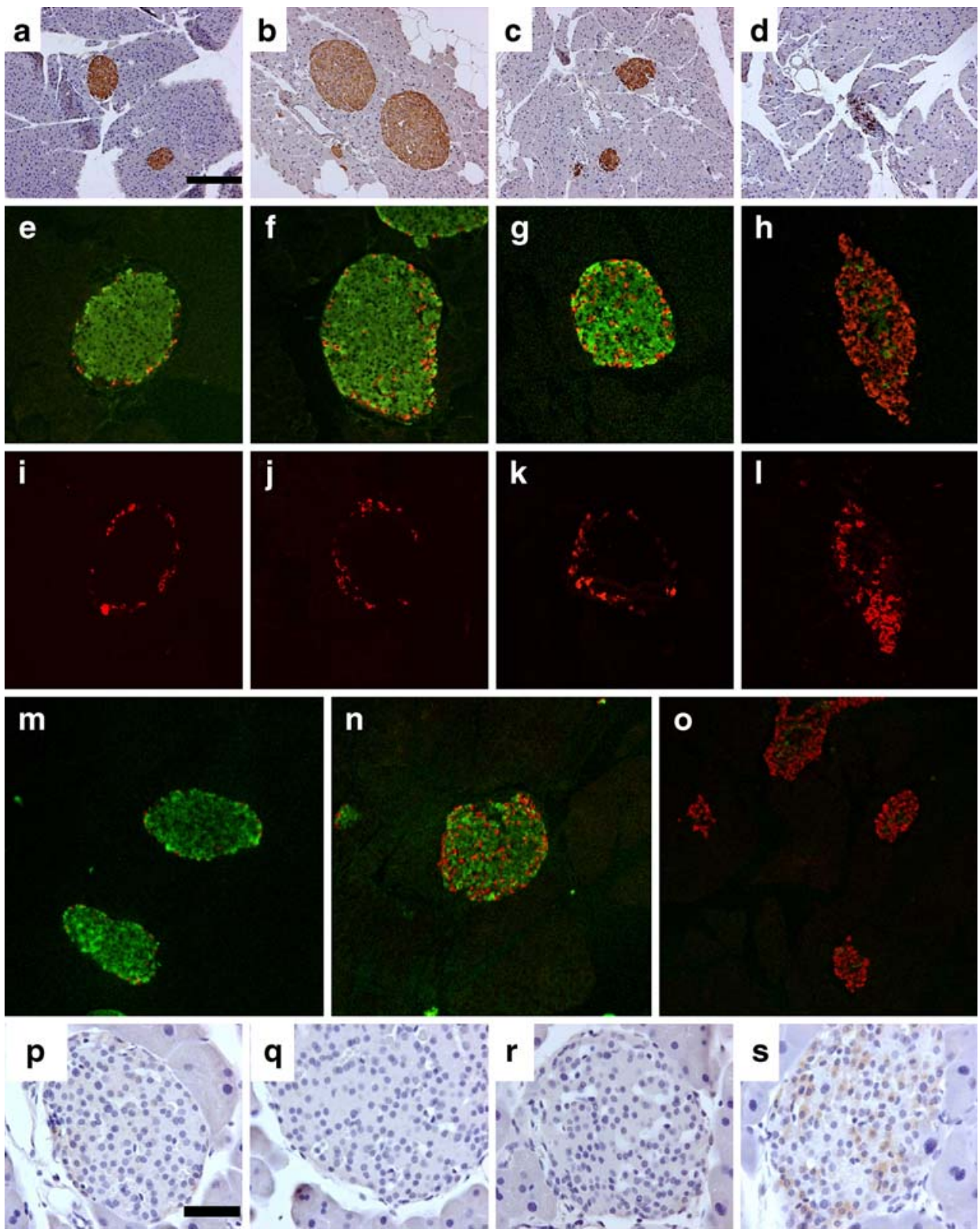

○
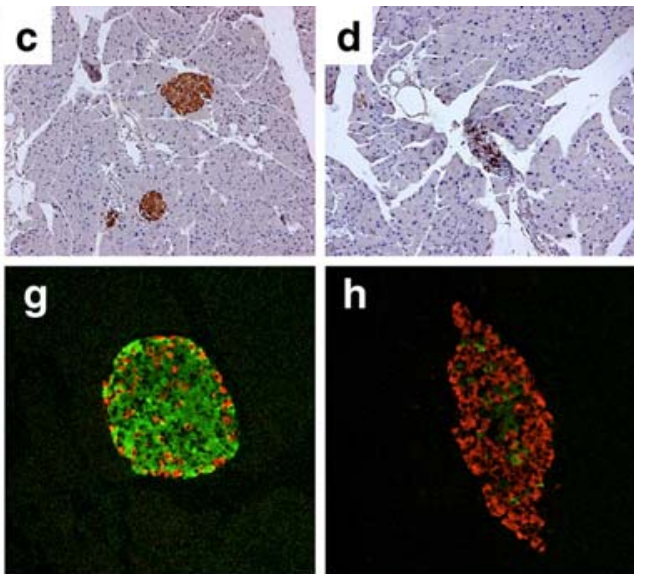

k
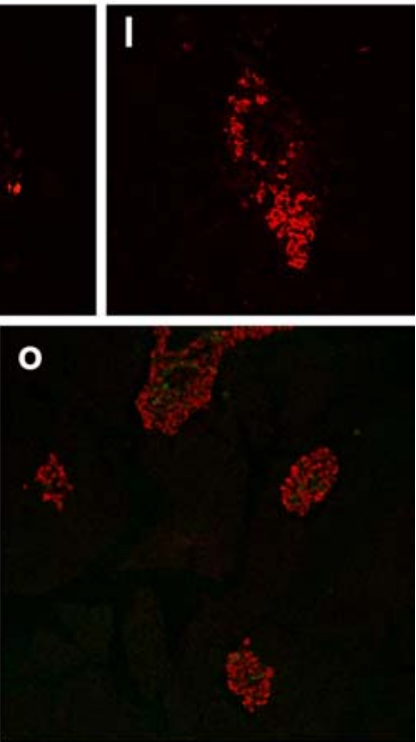

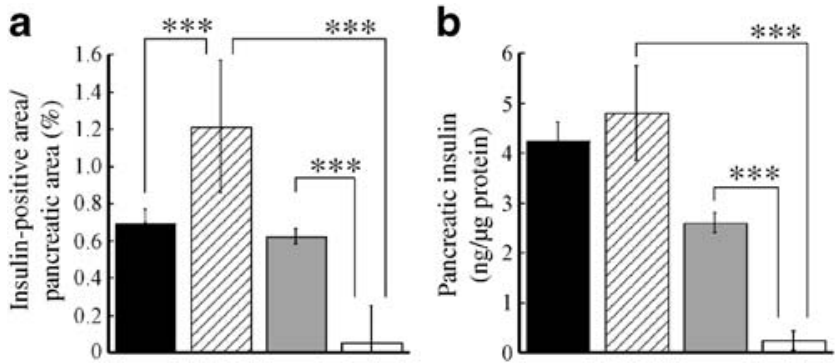

Fig. 4 Insulin-positive areas and insulin content of pancreases. a Ratios of total insulin-positive area to the entire pancreatic area were estimated for $W f S 1^{+/+}$a/a (WT, black bars), $W f_{S} 1^{+/+} A^{y} / a$ (hatched bars), $W f_{S} 1^{-/-} a / a$ (grey bars) and the $W f_{S} 1^{--} A^{y} / a$ (white bars) mice at age 24 weeks. At least five sections from each mouse were prepared and examined. Data are means $\pm \mathrm{SE}$ from four animals for each group. $* * * p<0.001$. b Insulin contents extracted from whole pancreases of WT, $W f_{S} I^{+/+} A^{y} / a, W f_{S} 1^{-/-} a / a$ and $W f_{S} 1^{-/-} A^{y} / a$ mice (key as above) at age 24 weeks (means \pm SE, $n=7$ ). ${ }^{* * *} p<0.001$

24 weeks of age, whereas glucagon-positive alpha cells and somatostatin-positive delta cells were preserved (Fig. 3h, 1). This selective beta cell loss was due to apoptotic cell death as indicated by caspase- 3 activation in islets of 16 -week-old mice (Fig. 3p-s).

Ultrastructural analysis We performed ultrastructural analyses of pancreatic beta cells from 12-week-old mice using electron microscopy. The beta cells were distinguished from alpha and delta cells by the appearance of their secretory granules. The beta cell granules had a white halo, not evident in alpha and delta cell granules.

In $A^{y} / a$ mice pancreatic beta cells, rough ER was well developed and structurally indistinguishable from that of WT mice (Fig. 5a, b, e, f). In $W f_{s} 1^{-/}$a/a mice, ER was dilated and beta cell secretory granules were electron-lucent in some pancreatic beta cells (Fig. 5c, g). In contrast, in $W f_{S} 1^{-1-} A^{y} / a$ mice, ER was severely dilated in almost all pancreatic beta cells and secretory granules were reduced in size and electron density (Fig. 5d, h). In addition, mitochondrial swelling was observed in these beta cells. ER abnormality appears to be a common finding in rodent models of ER stress-related beta cell failure [26, 29, 30]. Riggs et al. reported similar findings in their beta cellspecific $W f_{S} 1$ knockout mouse [22]. Changes were milder in their mice than in our $W f_{S} 1^{-/-} A^{y} / a$ mice and no mitochondrial abnormalities were mentioned. The difference may represent different stages of the same process.

Unfolded protein response in pancreatic islets of obese and $W f_{S} 1^{-/}$mice Our group and others have shown that $W f_{S} 1^{-/}$ beta cells are susceptible to ER stress and that WFS1 deficiency itself evokes the UPR [15, 20, 22]. If insulin resistance induces ER stress in pancreatic beta cells via increased demand for insulin biosynthesis and secretion, beta cell death would presumably be accelerated in $\mathrm{WfS}_{\mathrm{S}}{ }^{-/}$mice that become insulin-resistant. To examine this possibility, we first analysed WFS1 protein levels and the UPR in beta cells under insulin-resistant conditions. Western blot analysis at 12 weeks, when some mice were already hyperglycaemic, but more than half remained essentially normoglycaemic (Fig. 1b), revealed WFS1 protein levels to be increased in obese $W f_{S} I^{+/+} A^{y} / a$ murine islets as compared with those in $W f S I^{+/+}$a/a (WT) mice (Fig. 6a). Levels of ER chaperones $94 \mathrm{kDa}$ glucose-regulated protein (GRP94) and $78 \mathrm{kDa}$ glucose-regulated protein (GRP78) were also apparently increased in $W f_{S} I^{+/+} A^{y} / a$ and $W f_{S} 1^{-/-}$a/a mice as compared
Fig. 5 Electron micrograph of pancreatic beta cells. Ultrastructural analysis using electron microscopy was performed on islets from $W f_{S} 1^{+/+} a / a(\mathrm{WT})$ (a, e), $W f_{s} I^{+/+} A^{y} / a(\mathbf{b}, \mathbf{f})$, $W f_{S} 1^{-1-}$ a/a (c, g) and $W f_{S} 1^{-1}$ $A^{y} / a$ mice $(\mathbf{d}, \mathbf{h})$ at age 12 weeks. Magnification was as shown, i.e. lower $(\mathbf{a}-\mathbf{d})$ and higher (e-h). M, mitochondrion; $\mathrm{N}$, nucleus; SG, secretory granule; V, blood vessel
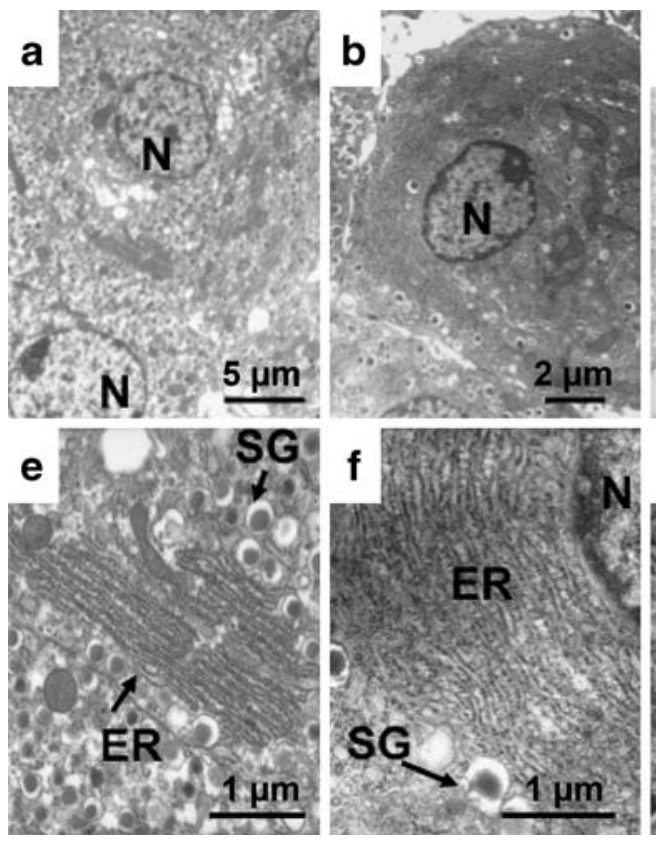

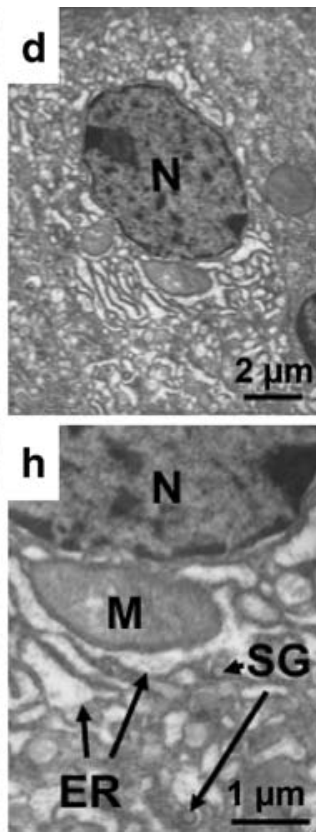



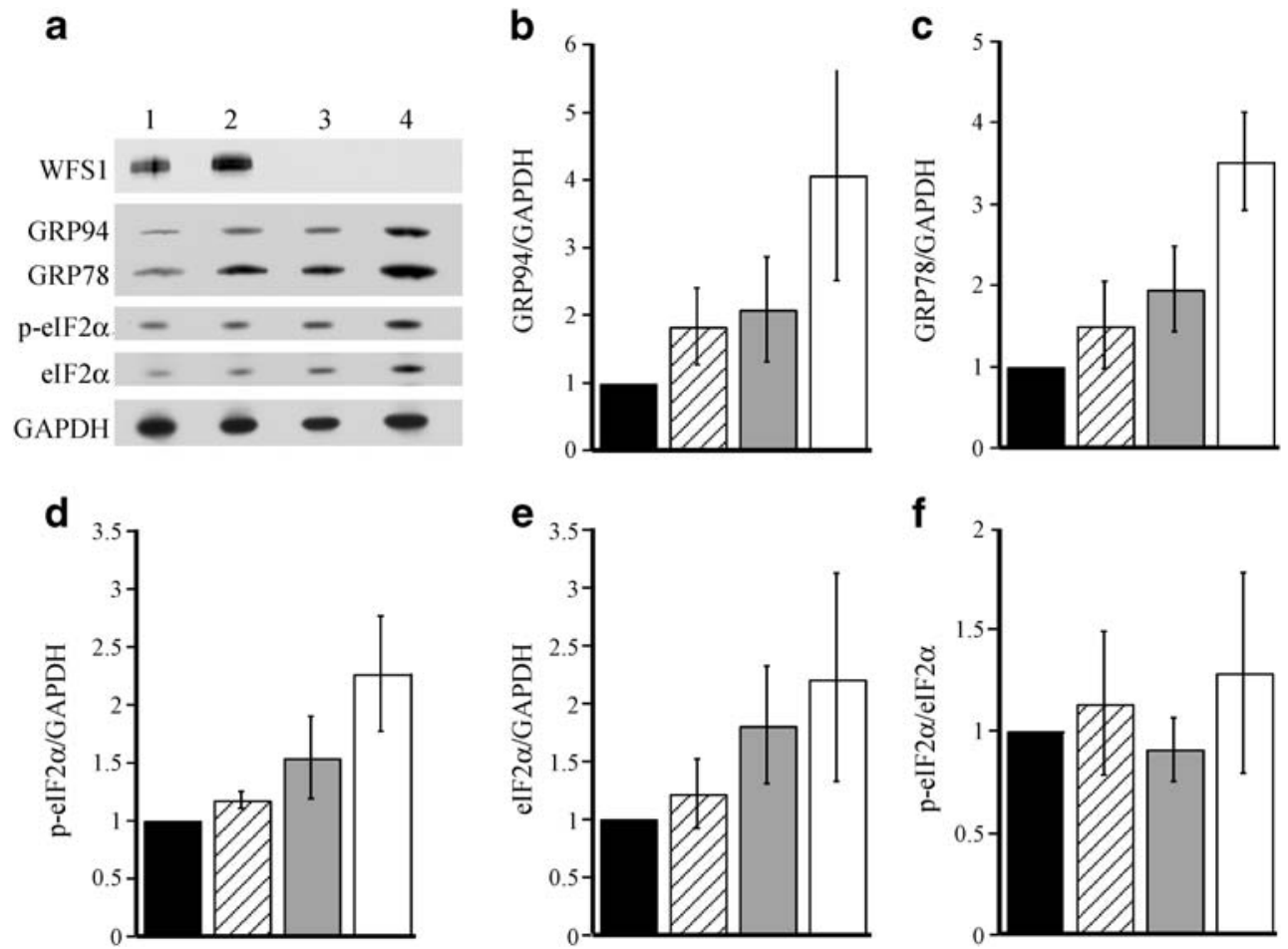

Fig. 6 Unfolded protein responses of pancreatic islets. a Isolated murine islets were subjected to SDS/PAGE and blotted using antibodies directed against WFS1 (N-terminus), C-terminal lys-asp-glu-leu (GRP94, GRP78), eIF $2 \alpha$, phosphorylated eIF $2 \alpha$ (p-eIF $2 \alpha$ ) and glyceraldehyde 3-phosphate dehydrogenase (GAPDH). Lane 1, Wfs $I^{+/ 4}$ a/a (WT); lane 2, $\mathrm{Wfs}^{+/+} A^{y} / a$; lane $3, \mathrm{Wfs}^{--}$a/a; lane 4, $\mathrm{Wfs}^{-/} A^{y} / \mathrm{a}$. The blot is representative of experiments repeated three times. b-f Summary of respective protein/

GAPDH levels from three independent experiments. Data (means \pm SE) are expressed relative to those of the $W f_{S} I^{+/+}$a/a (WT) islet preparation. Although the differences did not reach statistical significance, the UPR tended to be enhanced in $\mathrm{WfS}^{+/+} A^{y / a}$ (hatched bars) and $\mathrm{Wfs}^{-/}$a/a (grey bars) mice as compared with the WT $\left(\mathrm{Wf}^{+/+}\right.$a/a) (black bars) mice, and appeared to be further enhanced in $\mathrm{WfS}^{-/} A^{y / a}$ (white bars) mice. Experiments were performed using 12-week-old mice

with WT mice (Fig. 6a-c). Therefore, ER stress had been triggered in $A^{y} / a$ and $W f s 1^{--}$mice. In $W f s 1^{-/-} A^{y} / a$ mice, levels of these ER chaperones appeared to be further increased (Fig. 6a-c). Phosphorylation of the translation initiation factor-2, subunit $\alpha$ (eIF $2 \alpha)$ attenuates protein translation under ER stress conditions. Similar changes were observed in total eIF $2 \alpha$ protein and phosphorylated eIF $2 \alpha$ amounts in the islets of $W f_{S} I^{+/+} A^{y} / a, W f_{S} 1^{-/} a / a$ and $W f_{s} 1^{-/-} A^{y} / a$ mice (Fig. 6a, d-f). We also measured Grp 78 (also known as Hspa5), Grp94 (also known as Hsp90b1) and spliced Xbpl mRNA expression in 8-week-old mice islets. A similar trend was observed, although changes were less prominent at this age (ESM Fig. 2). These data suggest that $A^{y} / a$ murine islets are exposed to ER stress and that increased ER stress is among the likely causes of rapid and prominent beta cell apoptosis in $W f S 1^{-/-} A^{y} / a$ murine islets.

Pioglitazone prevented beta cell loss and diabetes in $\mathrm{WfS}_{\mathrm{S}} \mathrm{I}^{-/}$ $A^{y} / a$ mice Our observations suggest that beta cell overload markedly accelerates beta cell death and diabetes development in $W f_{S} 1^{-/-}$a/a mice. Therefore, we attempted to reduce this beta cell overload, which is likely to be due to obesity-associated insulin resistance, with pioglitazone treatment. Mice were allowed free access to normal chow containing $0.01 \%$ pioglitazone immediately after weaning (4 weeks of age). The average dose of pioglitazone was estimated to be $15 \mathrm{mg} \mathrm{kg}^{-1}$ day $^{-1}$.

Pioglitazone ameliorated insulin resistance as assessed by the non-fasting insulin levels in $W f_{S} I^{+/+} A^{y} / a$ mice (mean non-fasting insulin without pioglitazone 513.5 \pm $49.9 \mathrm{pmol} / \mathrm{l}, n=13$ vs with pioglitazone $326.9 \pm 61.0 \mathrm{pmol} /$ $1, n=7, p<0.05)$ at 12 weeks of age. Serum triacylglycerol levels were also markedly improved (Fig. 7). The $W f s 1^{-1-}$ $A^{y} / a$ mice gained more weight with pioglitazone treatment. As early as 7 weeks of age, $W f s 1^{-/-} A^{y} / a$ mice treated with pioglitazone were heavier $(28.7 \pm 0.7 \mathrm{~g}, n=11)$ than $W f_{S} I^{+/+}$ $A^{y} / a(25.5 \pm 0.7 \mathrm{~g}, n=15, p<0.01)$ and $W f s 1^{-/-} A^{y} / a(26.0 \pm$ $0.4 \mathrm{~g}, n=20, p<0.01$ ) mice fed normal chow (Fig. 8a). Despite the increased body weight, pioglitazone prevented diabetes development. Average non-fasted blood glucose levels were significantly lower in pioglitazone-treated $W f_{S} 1^{-/-} A^{y} / a$ mice than in untreated $W f_{S} 1^{-/} A^{y} / a$ mice $(12.9 \pm 0.9$ vs $20.5 \pm 1.9 \mathrm{mmol} / \mathrm{l}, p<0.002)$ at 16 weeks (Fig. 8b). Histological analyses revealed pancreatic beta cells to be very well preserved in pioglitazone-treated $W f_{S} 1^{-/-} A^{y} / a$ mice (Fig. 8c-f). 


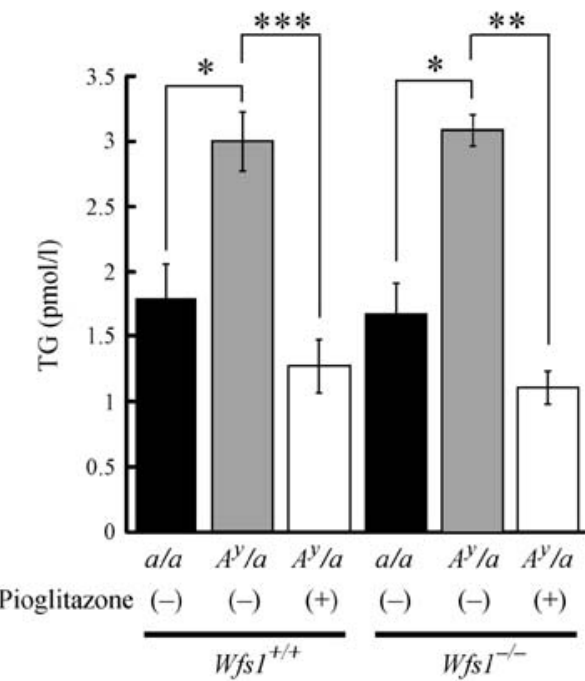

Fig. 7 Serum triacylglycerol (TG) levels with/without pioglitazone. Serum triacylglycerol levels were measured in 12-week-old mice. After weaning (4 weeks of age), the mice were fed standard mouse chow with/without $0.01 \%$ pioglitazone. Values are means \pm SE from three to five mice. ${ }^{*} p<0.05,{ }^{*} p<0.01,{ }^{* * *} p<0.001$

Pioglitazone did not suppress the UPR To investigate whether pioglitazone treatment reduces ER stress in pancreatic beta cells, we examined UPR activation by Western blot analysis using isolated murine islets. Interestingly and unexpectedly, pioglitazone did not reduce either ER chaperones or eIF2 $\alpha$ levels/phosphorylation in $W f_{S} 1^{-/-}$ $a / a$ and $W f_{S} 1^{-/-} A^{y} / a$ mice (Fig. 9a, ESM Fig. 3). Similar results were obtained for spliced Xbp1, Grp78, Grp94 and Chop (also known as Ddit3) mRNA expression in 8-week-old mice islets (ESM Fig. 2).

Electron microscopic examination revealed markedly improved ER appearance in $W f_{S} 1^{-/-} A^{y} / a$ pancreatic beta cells after pioglitazone treatment (Fig. 9b-e, see also Fig. 5). Without the treatment, almost all beta cells had markedly distended ER (Fig. 9b, c). However, after the treatment, the ER distension was markedly reduced and some beta cells appeared to be normal (Fig. 9d, e), although heterogeneity was observed among the cells.

\section{Discussion}

Here we demonstrated that $W f s 1^{-/} A^{y} / a$ mice on a C57BL/ $6 \mathrm{~J}$ background develop early-onset insulin-deficient diabetes mellitus as early as 6 weeks of age and that most are overtly diabetic by the 16th week, whereas neither $W f_{S} 1$-deficient $W f_{S} 1^{-/-}$a/a nor obese agouti yellow $\left(W f_{S} 1^{+/+} A^{y} / a\right)$ mice had developed overt diabetes by the 24th week. In $W f S 1^{-/}$ $A^{y} / a$ murine islets, beta cell mass was dramatically decreased due to increased beta cell apoptosis. WFS1 protein clearly plays a pivotal role in beta cell survival.
Our previous study had demonstrated that approximately half of $W f_{S} 1^{-1}$ mice develop diabetes when they have the hybrid genetic background of C57BL/6J and 129Sv, while. unexpectedly with the C57BL/6J background, there is no apparent increase in blood glucose levels even at 36 weeks [15]. Because beta cells of $W f_{S} 1^{--}$mice were also shown to be susceptible to ER stress in ex-vivo experiments and cultured cells $[15,21]$, we sought to test this in the in vivo model.
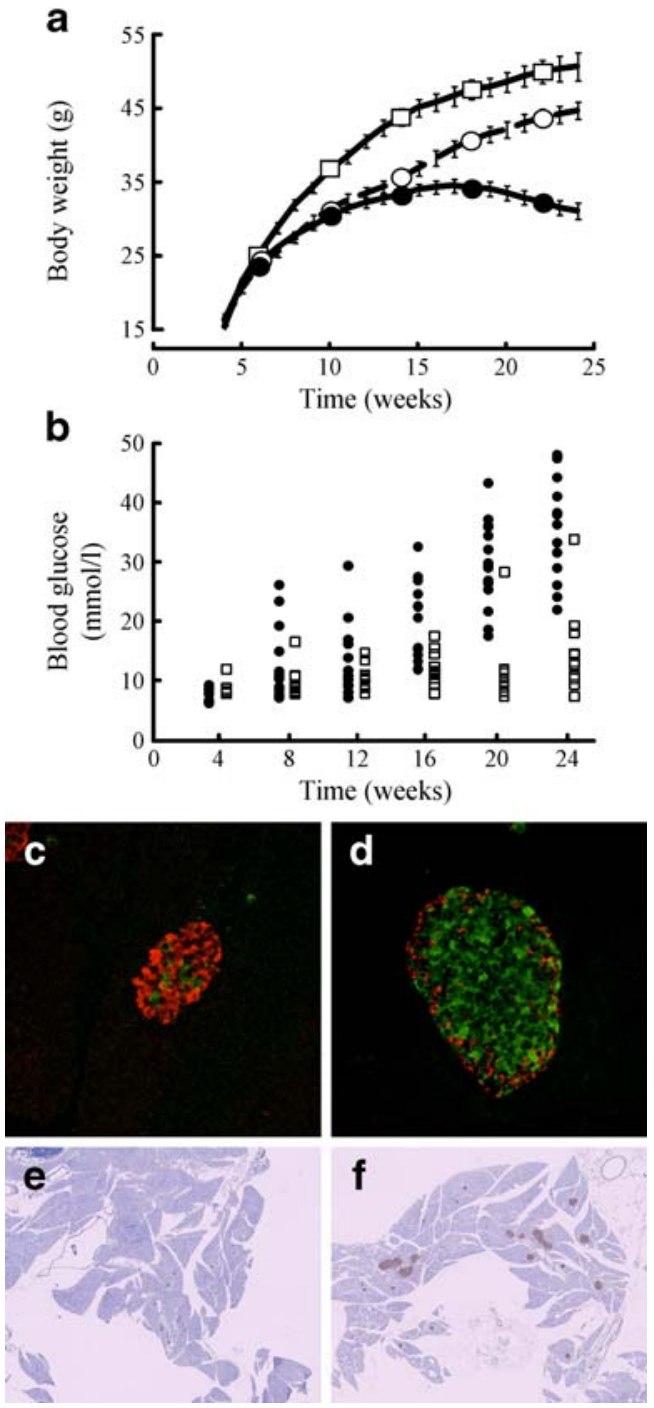

Fig. 8 Pioglitazone prevents diabetes and beta cell loss. The standard mouse chow with $0.01 \%$ pioglitazone was started at 4 and continued until 24 weeks of age in $W f_{S} 1^{-/} A^{y} / a$ mice. a Graph showing body weight changes (means $\pm \mathrm{SE}, n=11-20$ ) and (b) non-fasted blood glucose levels $(n=11-16)$. Black circles, $W f_{s} 1^{-/-} A^{y} / a$ mice without treatment; squares, $W f_{S} 1^{-/-} A^{y} / a$ mice with pioglitazone treatment; white circles, control $W f_{S} 1^{+/+} A^{y} / a$ mice. c Insulin (green) and glucagon (red) were stained in pancreatic sections from $W f_{s} 1^{-/-} A^{y} / a$ mice and (d) from pioglitazone-treated $W f_{S} 1^{-/-} A^{y} / a$ mice at 24 weeks of age. e Insulin (brown) was stained in pancreatic sections from $W f_{S} 1^{-/} A^{y} / a$ mice and (f) from pioglitazone-treated $W f_{S} 1^{-/-} A^{y / a}$ mice at 24 weeks of age 
a
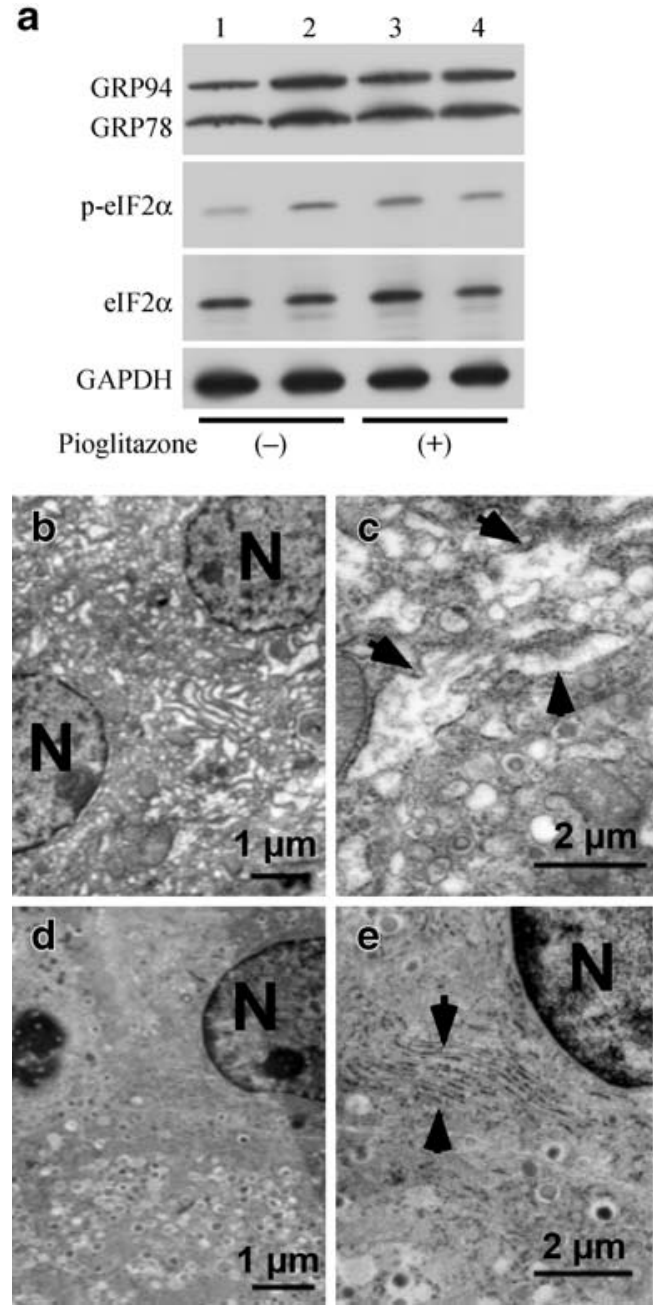

Fig. 9 Unfolded protein responses and ultrastructural changes in beta cells after pioglitazone treatment. a $W f_{S} 1^{-/}$a/a (lanes 1,3) and $W f_{S} 1^{-/-} A^{y} / a$ (lanes 2,4) mice were fed standard mouse chow with/ without $0.01 \%$ pioglitazone after weaning ( 4 weeks of age). Isolated murine islets at 12 weeks of age were subjected to SDS/PAGE and blotted using antibodies directed against WFS1 (N-terminus), Cterminal lys-asp-glu-leu (GRP94, GRP78), eIF2 $\alpha$, phosphorylated eIF $2 \alpha$ (p-eIF2 $\alpha$ ) and glyceraldehyde 3-phosphate dehydrogenase (GAPDH). The blot is representative of three independent experiments. Densitometric quantification of these results is presented in ESM Fig. 3). Electron micrographs of islets from $\mathrm{WfS}_{S} \mathrm{1}^{-/} A^{y} / a$ mice (12-week-old) without $(\mathbf{b}, \mathbf{c})$ or with $(\mathbf{d}, \mathbf{e})$ pioglitazone treatment. Arrows, ER; N, nucleus

The $A^{y} / a$ mouse is a genetic model of mild obesity/ insulin resistance with compensatory beta cell hyperplasia [31] (Figs 1 and 3). Increased demand for insulin biosynthesis and secretion has been thought to cause ER stress in pancreatic beta cells, and here, in fact, we demonstrated, in $A^{y} / a$ murine islets, that ER chaperone expression was apparently increased at 12 weeks of age (Fig. 6). Similar results have been demonstrated in another insulin-resistant mouse model [7]. In addition, WFS1 protein levels were also increased (Fig. 6a). Our group and others have shown WFS1 protein levels to be upregulated by ER stress [19, 20, 35]. These data suggest that increased insulin demand under insulin-resistant conditions produces chronic ER stress in beta cells. In addition, NEFA, which are elevated in these insulin-resistant models, may also contribute to the activation of UPR [32]. In this regard, Lipson et al. recently demonstrated that hyperglycaemia activates inositol-requiring protein-1 (IRE1) $\alpha$, an ER-resident transmembrane protein kinase regulating UPR in beta cells. Although IRE1 $\alpha$ activation by transient hyperglycaemia is beneficial to beta cells, chronically sustained hyperglycaemia causes ER stress and suppresses insulin gene expression [36]. Glucose regulation of the UPR has also been reported [37].

Dramatically decreased beta cell numbers in $\mathrm{WfS}_{S}{1^{--}}^{-1} A^{y / a}$ mice suggest that increased insulin demand triggers pancreatic beta cell apoptosis in $W f s 1$-deficient mice. ER stress induces WFS1 protein production and lack of this protein itself enhances the UPR [15, 19-21]. This was true in our mice (Fig. 6), with the UPR apparently further enhanced in mildly obese $W f_{S} 1^{-/-} A^{y} / a$ mice. These data support the hypothesis that beta cell loss in Wolfram syndrome is, at least partly, caused by increased ER stress in beta cells. Although the precise function of ER-resident WFS1 protein remains unknown, our overall results suggest that this protein is likely to protect beta cells from ER stress-induced apoptosis and that Wolfram syndrome is an ER stress-related disease.

In patients with type 2 diabetes, very gradual, but progressive beta cell loss is caused by many factors, both genetic and acquired. One well-established mechanism of acquired beta cell loss is oxidative stress, which appears to be a major mediator of glucotoxicity [38]. We observed 4hydroxy-2-nonenal-modified protein, an oxidative stress marker, in $W f_{S} 1^{-/-} A^{y} / a$ murine islets at age 16 weeks (data not shown), suggesting that oxidative stress is also involved in beta cell apoptosis. Oxidative stress is likely to have been secondary to chronic hyperglycaemia because most $\mathrm{WfS}_{S} 1^{-/}$ $A^{y} / a$ mice had developed hyperglycaemia by this age (Fig. 1b). In $W f S 1^{-/} A^{y} / a$ mice, the vicious cycle associated with ER stress and oxidative stress probably exacerbates beta cell apoptosis. In this regard, it is again worth emphasising that insulin resistance induces ER stress in pancreatic beta cells [7]. Currently, we do not know the full extent of ER stress involvement in beta cell failure in human type 2 diabetes. However, it is possible that this vicious cycle associated with ER stress and oxidative stress plays an important role in beta cell deterioration [39].

Pioglitazone treatment almost completely prevented the development of diabetes and beta cell loss in $\mathrm{WfS}_{S} \mathrm{I}^{--} \mathrm{A}^{y} / \mathrm{a}$ mice. One simple explanation is that insulin resistance was ameliorated by pioglitazone treatment, reducing ER stress in pancreatic beta cells and preventing beta cell death. 
However, the mechanism may not be so simple. Unexpectedly, the UPR, represented by ER chaperone expression, was not significantly reduced (Fig. 9a, ESM Figs 2 and 3) to the extent that we expected from the remarkable level of diabetes prevention. Because the UPR is a protective response against ER stress, an apoptotic pathway may have been preferentially suppressed under these conditions. Several pathways are reportedly involved in ER stress-induced apoptosis, including the C/EBP-homologous protein (CHOP), the IRE1-TNF receptor-associated factor 2 (TRAF2)-apoptosis signal-regulating kinase 1 (ASK1), and the caspase 12 pathways [40]. The precise mechanism whereby pioglitazone prevented apoptosis in beta cells awaits determination. The beta cell protection exerted by thiazolidinediones including pioglitazone has been demonstrated in other rodent models [41, 42] and also in humans [43]. Although the precise mechanisms are not fully understood, one possibility is an indirect action through improvements in systemic glucose and lipid metabolism. Another mechanism involves direct actions on pancreatic beta cells [44]. Recent reports have demonstrated that thiazolidinediones directly improve beta cell function [45], ameliorate lipotoxicity [46] and prevent beta cell apoptosis $[47,48]$. In $W f_{S} 1^{-/-} A^{y} / a$ mice, direct protective effects, as well as indirect effects, are likely to be exerted. Elucidation of the mechanism whereby pioglitazone directly protects beta cells against apoptosis in $\mathrm{WfS}_{\mathrm{S}} \mathrm{I}^{--}$ $A^{y} / a$ mice would provide insights into the mechanism of beta cell death in patients with Wolfram syndrome, as well as the function of WFS1 protein in beta cells.

This is one of a few good models showing that one genetic defect predisposes beta cells to profound failure upon ER stress induced by systemic insulin resistance [30, 49]. Our findings are important for the understanding of the molecular pathophysiology of Wolfram syndrome. In addition, a common process may be involved in conventional type 2 diabetes patients, whose beta cells decrease very slowly but progressively. In this context, a recent report has confirmed that common variants in the WFS1 gene confer risk of type 2 diabetes [50]. Therefore knowledge from this model would help us to understand the mechanisms of, and to develop a way of preventing beta cell loss in patients with conventional type 2 diabetes mellitus.

Acknowledgements We thank M. Nishimura (Nagoya University Graduate School of Medicine) for kindly providing C57BL/ 6JHamSlc- $\mathrm{A}^{\mathrm{y}}$ mice. This study was supported in part by Grants-inAid for Scientific Research (grant no16390096, 18390103 and 20390093 to Y. Tanizawa) from the Ministry of Education, Culture, Sports, Science and Technology of Japan, grant no. 16790510 (to K. Ueda) from the Japan Society for the Promotion of Science, grant H16-genome-003 (to Y. Oka and Y. Tanizawa) from the Ministry of
Health, Labour and Welfare of Japan, and a grant from the Takeda Science Foundation (to Y. Tanizawa).

Duality of interest The authors declare that there is no duality of interest associated with this manuscript.

\section{References}

1. Rhodes CJ (2005) Type 2 diabetes - a matter of beta-cell life and death? Science 307:380-384

2. Butler AE, Janson J, Bonner-Weir S, Ritzel R, Rizza RA, Butler PC (2003) Beta-cell deficit and increased beta-cell apoptosis in humans with type 2 diabetes. Diabetes 52:102-110

3. Sakuraba H, Mizukami H, Yagihashi N, Wada R, Hanyu C, Yagihashi S (2002) Reduced beta-cell mass and expression of oxidative stress-related DNA damage in the islet of Japanese Type II diabetic patients. Diabetologia 45:85-96

4. Poitout V, Robertson RP (2008) Glucolipotoxicity: fuel excess and beta-cell dysfunction. Endocr Rev 29:351-366

5. Eizirik DL, Cardozo AK, Cnop M (2008) The role for endoplasmic reticulum stress in diabetes mellitus. Endocr Rev 29:42-61

6. Marchetti P, Bugliani M, Lupi R et al (2007) The endoplasmic reticulum in pancreatic beta cells of type 2 diabetes patients. Diabetologia 50:2486-2494

7. Laybutt DR, Preston AM, Akerfeldt MC et al (2007) Endoplasmic reticulum stress contributes to beta cell apoptosis in type 2 diabetes. Diabetologia 50:752-763

8. Barrett TG, Bundey SE (1997) Wolfram (DIDMOAD) syndrome. J Med Genet 34:838-841

9. Barrett TG, Bundey SE, Macleod AF (1995) Neurodegeneration and diabetes: UK nationwide study of Wolfram (DIDMOAD) syndrome. Lancet 346:1458-1463

10. Karasik A, O'Hara C, Srikanta S et al (1989) Genetically programmed selective islet beta-cell loss in diabetic subjects with Wolfram's syndrome. Diabetes Care 12:135-138

11. Inoue $\mathrm{H}$, Tanizawa $\mathrm{Y}$, Wasson $\mathrm{J}$ et al (1998) A gene encoding a transmembrane protein is mutated in patients with diabetes mellitus and optic atrophy (Wolfram syndrome). Nat Genet 20:143-148

12. Strom TM, Hortnagel K, Hofmann S et al (1998) Diabetes insipidus, diabetes mellitus, optic atrophy and deafness (DIDMOAD) caused by mutations in a novel gene (wolframin) coding for a predicted transmembrane protein. Hum Mol Genet 7:2021-2028

13. Takeda K, Inoue H, Tanizawa Y et al (2001) WFS1 (Wolfram syndrome 1) gene product: predominant subcellular localization to endoplasmic reticulum in cultured cells and neuronal expression in rat brain. Hum Mol Genet 10:477-484

14. Hofmann S, Philbrook C, Gerbitz KD, Bauer MF (2003) Wolfram syndrome: structural and functional analyses of mutant and wildtype wolframin, the WFS1 gene product. Hum Mol Genet 12:2003-2012

15. Ishihara H, Takeda S, Tamura A et al (2004) Disruption of the WFS1 gene in mice causes progressive beta-cell loss and impaired stimulus-secretion coupling in insulin secretion. Hum Mol Genet 13:1159-1170

16. Osman AA, Saito M, Makepeace C, Permutt MA, Schlesinger P, Mueckler M (2003) Wolframin expression induces novel ion channel activity in endoplasmic reticulum membranes and increases intracellular calcium. J Biol Chem 278:52755-52762 
17. Takei D, Ishihara H, Yamaguchi S et al (2006) WFS1 protein modulates the free $\mathrm{Ca}^{2+}$ concentration in the endoplasmic reticulum. FEBS Lett 580:5635-5640

18. Zatyka M, Ricketts C, da Silva Xavier G et al (2008) Sodiumpotassium ATPase 1 subunit is a molecular partner of Wolframin, an endoplasmic reticulum protein involved in ER stress. Hum Mol Genet 17:190-200

19. Fonseca SG, Fukuma M, Lipson KL et al (2005) WFS1 is a novel component of the unfolded protein response and maintains homeostasis of the endoplasmic reticulum in pancreatic beta-cells. J Biol Chem 280:39609-39615

20. Ueda K, Kawano J, Takeda K et al (2005) Endoplasmic reticulum stress induces Wfs 1 gene expression in pancreatic beta-cells via transcriptional activation. Eur J Endocrinol 153:167-176

21. Yamada T, Ishihara H, Tamura A et al (2006) WFS1-deficiency increases endoplasmic reticulum stress, impairs cell cycle progression and triggers the apoptotic pathway specifically in pancreatic beta-cells. Hum Mol Genet 15:1600-1609

22. Riggs AC, Bernal-Mizrachi E, Ohsugi M et al (2005) Mice conditionally lacking the Wolfram gene in pancreatic islet beta cells exhibit diabetes as a result of enhanced endoplasmic reticulum stress and apoptosis. Diabetologia 48:2313-2321

23. Schroder M, Kaufman RJ (2005) The mammalian unfolded protein response. Annu Rev Biochem 74:739-789

24. Ron D, Walter P (2007) Signal integration in the endoplasmic reticulum unfolded protein response. Nat Rev Mol Cell Biol 8:519-529

25. Scheuner D, Kaufman RJ (2008) The unfolded protein response: a pathway that links insulin demand with beta-cell failure and diabetes. Endocr Rev 29:317-333

26. Harding HP, Zeng H, Zhang Y et al (2001) Diabetes mellitus and exocrine pancreatic dysfunction in perk ${ }^{-/}$mice reveals a role for translational control in secretory cell survival. Mol Cell 7:11531163

27. Delepine M, Nicolino M, Barrett T, Golamaully M, Lathrop GM, Julier C (2000) EIF2AK3, encoding translation initiation factor 2alpha kinase 3, is mutated in patients with Wolcott-Rallison syndrome. Nat Genet 25:406-409

28. Scheuner D, Song B, McEwen E et al (2001) Translational control is required for the unfolded protein response and in vivo glucose homeostasis. Mol Cell 7:1165-1176

29. Wang J, Takeuchi T, Tanaka S et al (1999) A mutation in the insulin 2 gene induces diabetes with severe pancreatic beta-cell dysfunction in the Mody mouse. J Clin Invest 103:27-37

30. Scheuner D, Vander MD, Song B et al (2005) Control of mRNA translation preserves endoplasmic reticulum function in beta cells and maintains glucose homeostasis. Nat Med 11:757-764

31. Wolff GL, Roberts DW, Mountjoy KG (1999) Physiological consequences of ectopic agouti gene expression: the yellow obese mouse syndrome. Physiol Genomics 11:151-163

32. Cunha DA, Hekerman $P$, Ladrière $L$ et al (2008) Initiation and execution of lipotoxic ER stress in pancreatic beta-cells. J Cell Sci 121:2308-2318

33. Usui S, Hara Y, Hosaki S, Okazaki M (2002) A new on-line dual enzymatic method for simultaneous quantification of cholesterol and triglycerides in lipoproteins by HPLC. J Lipid Res 43:805-814

34. Oka Y, Asano T, Shibasaki Y, Kasuga M, Kanazawa Y, Takaku F (1988) Studies with antipeptide antibody suggest the presence of at least two types of glucose transporter in rat brain and adipocyte. J Biol Chem 263:13432-13439

35. Yamaguchi S, Ishihara H, Tamura A (2004) Endoplasmic reticulum stress and $\mathrm{N}$-glycosylation modulate expression of WFS1 protein. Biochem Biophys Res Commun 325:250-256

36. Lipson KL, Fonseca SG, Ishigaki S et al (2006) Regulation of insulin biosynthesis in pancreatic beta cells by an endoplasmic reticulum-resident protein kinase IRE1. Cell Metab 4:245-254

37. Elouil H, Bensellam M, Guiot $Y$ et al (2007) Acute nutrient regulation of the unfolded protein response and integrated stress response in cultured rat pancreatic islets. Diabetologia 50:14421452

38. Robertson RP, Harmon JS (2006) Diabetes, glucose toxicity, and oxidative stress: a case of double jeopardy for the pancreatic islet beta cell. Free Radic Biol Med 41:177-184

39. Malhotra JD, Kaufman RJ (2007) Endoplasmic reticulum stress and oxidative stress: a vicious cycle or a double-edged sword? Antioxid Redox Signal 9:2277-2293

40. Yoshida H (2007) ER stress and diseases. FEBS J 274:630-658

41. Ishida H, Takizawa M, Ozawa S (2004) Pioglitazone improves insulin secretory capacity and prevents the loss of beta-cell mass in obese diabetic $\mathrm{db} / \mathrm{db}$ mice: possible protection of beta cells from oxidative stress. Metabolism 53:488-494

42. Diani AR, Sawada G, Wyse B, Murray FT, Khan M (2004) Pioglitazone preserves pancreatic islet structure and insulin secretory function in three murine models of type 2 diabetes. Am J Physiol Endocrinol Metab 286:116-122

43. Dormandy JA, Charbonnel B, Eckland DJ et al (2005) Secondary prevention of macrovascular events in patients with type 2 diabetes in the PROactive Study (PROspective pioglitAzone Clinical Trial In macroVascular Events): a randomised controlled trial. Lancet 366:1279-1289

44. Rosen ED, Kulkarni RN, Sarraf P et al (2003) Targeted elimination of peroxisome proliferator-activated receptor gamma in beta cells leads to abnormalities in islet mass without compromising glucose homeostasis. Mol Cell Biol 23:7222-7229

45. Kim HI, Ahn YH (2004) Role of peroxisome proliferatoractivated receptor-gamma in the glucose-sensing apparatus of liver and beta-cells. Diabetes 53(Suppl 1):S60-S65

46. Saitoh Y, Chun-ping C, Noma K et al (2008) Pioglitazone attenuates fatty acid-induced oxidative stress and apoptosis in pancreatic beta-cells. Diabetes Obes Metab 10:564-573

47. Lin CY, Gurlo T, Haataja L, Hsueh WA, Butler PC (2005) Activation of peroxisome proliferator-activated receptor-gamma by rosiglitazone protects human islet cells against human islet amyloid polypeptide toxicity by a phosphatidylinositol 3'-kinasedependent pathway. J Clin Endocrinol Metab 90:6678-6686

48. Zeender E, Maedler K, Bosco D et al (2004) Pioglitazone and sodium salicylate protect human beta-cells against apoptosis and impaired function induced by glucose and interleukin-1beta. J Clin Endocrinol Metab 89:5059-5066

49. Huang C, Lin C, Haataja L et al (2007) High expression rates of human islet amyloid polypeptide induce endoplasmic reticulum stress-mediated beta-cell apoptosis, a characteristic of humans with type 2 but not type 1 diabetes. Diabetes 56:2016-2027

50. Sandhu MS, Weedon MN, Fawcett KA et al (2007) Common variants in WFS1 confer risk of type 2 diabetes. Nat Genet 39:951-953 